\title{
Wear and corrosion of niobium carbide coated AISI 52100 bearing steel
}

\author{
F.A.P. Fernandes ${ }^{\text {a,* }}$, J. Gallego ${ }^{\text {a }}$, C.A. Picon ${ }^{\text {b }}$, G. Tremiliosi Filho ${ }^{\text {c }}$, L.C. Casteletti ${ }^{\mathrm{d}}$ \\ a Departamento de Engenharia Mecânica, Faculdade de Engenharia de Ilha Solteira, Universidade Estadual Paulista, Av. Brasil Centro, n. 56, 15385-000 Ilha Solteira, SP, Brazil \\ ${ }^{\mathrm{b}}$ Departamento de Física e Química, Faculdade de Engenharia de Ilha Solteira, Universidade Estadual Paulista, Av. Brasil Centro, n. 56, 15385-000 Ilha Solteira, SP, Brazil \\ c Departamento de Físico-Química, Instituto de Química de São Carlos, Universidade de São Paulo, Av. Trabalhador São Carlense, n. 400, 13566-590 São Carlos, SP, Brazil \\ 'd Departamento de Engenharia de Materiais, Escola de Engenharia de São Carlos, Universidade de São Paulo, Av. João Dagnone, n. 1100, 13563-120 São Carlos, SP, Brazil
}

\section{A R T I C L E I N F O}

\section{Article history:}

Received 15 June 2015

Revised 13 August 2015

Accepted in revised form 17 August 2015

Available online 21 August 2015

\section{Keywords:}

Bearing steels

Thermo-reactive deposition

$\mathrm{NbC}$

Wear

Corrosion

\begin{abstract}
A B S T R A C T
Bearing steels must have high hardness, good wear resistance and dimensional stability. In the present work, the AISI 52100 bearing steel was selected as the substrate for a niobium carbide coating produced by a salt-bath thermo-reactive deposition process. The present work addresses the effect of niobium carbide coating on the wear and corrosion resistance of the abovementioned steel. A homogeneous layer composed solely by the cubic niobium carbide ( $\mathrm{NbC}$ ) was produced. The carbide coating yielded average hardness and elastic modulus of $26 \mathrm{GPa}$ and $361 \mathrm{GPa}$, respectively. No significant decarburization was detected beneath the case by means of hardness fluctuations. Dry wear tests resulted in worn volumes 10 times smaller for the NbC coated steel, comparatively to the untreated substrate, at three different applied loads. Corrosion tests in $\mathrm{NaCl}$ solution indicated an improved behavior for the carbide coated bearing steel at applied potentials inferior than $250 \mathrm{mV}$. At higher potentials, the electrolyte appears to penetrate trough the layer yielding wide corrosion caps.
\end{abstract}

(c) 2015 Elsevier B.V. All rights reserved.

\section{Introduction}

Coating of surfaces is one of the most versatile ways to enhance the performance of components with respect to wear and/or corrosion. Hard coatings can be produced by a wide range of processes requiring controlled atmospheres, vacuum and at high costs [1-4]. An alternative and cost-effective method is the thermo-reactive diffusion/deposition (TRD) technique that can be applied to obtain transition metal compound coatings on iron based alloys $[1,5]$. The process is usually performed in a salt-bath [4-6] or in the solid state [7-9].

During the TRD process the interstitial element (usually $\mathrm{C}$ and/ or $\mathrm{N}$ ) diffuse from the bulk towards the surface to meet a carbide/ nitride-forming element such as $\mathrm{V}, \mathrm{Nb}, \mathrm{Ti}$, Ta and $\mathrm{Cr}$. The diffused interstitials react with the carbide/nitride-forming element from the bath/ pack to produce a dense and metallurgically bonded coating at the substrate surface $[1,5]$. Such process is widely known to yield very high hardness, adhesion and a great potential for extreme wear applications $[6,10,11]$.

Niobium carbide $(\mathrm{NbC})$ is an example of a compound that can be obtained by the abovementioned TRD technique in molten borax. The carbide layer forms by the direct combination of carbon in the substrate with the dissolved niobium in the bath. Such formation is feasible due to its lower free energy for carbide formation and higher free energy for oxide formation than boron [12]. This carbide exhibits a number of interesting characteristics for tribological applications [13]. Additionally

\footnotetext{
* Corresponding author.

E-mail address: codoico@dem.feis.unesp.br (F.A.P. Fernandes).
}

to high hardness, NbC presents increased toughness and stiffness, an extremely high melting temperature $\left(3873^{\circ} \mathrm{C}\right)$ and chemical stability [14].

The vast majority of the literature deals with the growth kinetics of the carbide layers [15-17], its mechanical [18] and wear properties [10, 13]. Very few studies deal with the electrochemical behavior of carbide coatings produced by the TRD technique. In fact most of the work in the literature is dedicated to boronizing [19,20]. A study on pack chromizing found that protection against corrosion appears to increase with treatment time and temperature [8]. A recent research indicates that percentage of ferro-niobium added to the bath did not influence the corrosion resistance of the $\mathrm{NbC}$ layer. However, it is suggested that porosity slightly decreases as the amount of ferro-niobium increase and that porosity favors the corrosion process [21]. Therefore, it is important to understand the electrochemistry of such coatings in order to expand its possible application range.

Wear and corrosion related phenomena are recurrent problems in industry causing material losses that can further lead to a failure. In this respect, the present study focuses on the evaluation of wear properties and additionally the electrochemical response of niobium carbide layers produced by a salt-bath TRD process on a high carbon bearing steel. The selected substrate is the AISI 52100 steel which is one of the most common bearing steel applied in rolling contact and must have high hardness, good wear resistance and dimensional stability [22].

\section{Experimental}

Initially AISI 52100 square samples with dimensions of $20 \times 20 \mathrm{~mm}$ and thickness of $3 \mathrm{~mm}$ were ground up to 600 mesh emery paper and 
cleaned in ethanol. The AISI 52100 is a bearing steel also known as $100 \mathrm{Cr} 6$ and its nominal chemical composition in wt.\% is: $0.95-1.10 \% \mathrm{C}$, 0.15-0.35\% Si, 0.25-0.45\% Mn, 0.03\% P, 0.025\% S, 1.35-1.65\% Cr and Fe. Single values represent the maximum percentage of the element.

The salt bath, for depositing the carbide coating, was composed of $5 \mathrm{wt} . \%$ ferro-niobium (containing $65 \mathrm{wt} . \% \mathrm{Nb}$ and particle size $>150$ mesh), 3 wt.\% aluminum and 92 wt.\% sodium tetraborate $\left(\mathrm{Na}_{2} \mathrm{~B}_{4} \mathrm{O}_{7} \cdot 10 \mathrm{H}_{2} \mathrm{O}\right)$.

TRD treatments were performed in an open air pit-type furnace. Firstly, sodium tetraborate (borax) was molten in a steel container then aluminum and ferro-niobium added. Aluminum was applied as a reducing agent and ferro-niobium as the source of niobium [5]. The specimens were hanged in the homogenized melt at $1000{ }^{\circ} \mathrm{C}$ for $4 \mathrm{~h}$ and quenched in oil directly from the bath. The produced layer was characterized by X-ray diffraction, scanning electron microscopy (SEM), instrumented hardness measurements, micro-abrasive wear and corrosion testing. Prior to the measurements the samples were cleaned in boiling water and gently polished with alumina suspension $(1 \mu \mathrm{m})$ in order to remove any residue from the salt bath.

Instrumented hardness measurements were performed on a hot mounted cross section of a coated sample applying a Shimadzu dynamic ultra micro-hardness tester (DUH-211S), with a Vickers indenter. The test load was $50 \mathrm{mN}$ at a loading speed of approximately $3 \mathrm{mN} / \mathrm{s}$. The elastic modulus $(E)$ of the carbide layer and substrate were estimated as well and the indentations repeated at least 5 times. The elastic modulus of the indented specimens were evaluated based on a standardized method initially proposed by Oliver and Pharr [23], considering a fraction of the unloading curves and the Poisson ratio. For phase identification, X-ray diffraction (XRD) was performed on the surface of the samples using the Bragg-Brentano symmetric geometry in a Rigaku Gergerflex equipment with scanning angles ranging from 30 to $100^{\circ}$. The analyses were carried out employing copper $(\mathrm{Cu}) \mathrm{K} \alpha$ radiation and continuous scanning with a speed of $2^{\circ} / \mathrm{min}$.

Electron microscopy was applied on the cross section of the $\mathrm{NbC}$ coated steel using a scanning electron microscope (SEM), model LEO 440 with a tungsten filament, coupled with an EDS (energy dispersive spectroscopy) detector.

A micro-abrasive wear machine was applied for studying the tribology of coated and uncoated systems. Tests were performed in a fixedball machine (described elsewhere $[6,11]$ ) without abrasive and using a AISI 52100 steel sphere of $25.4 \mathrm{~mm}$ in diameter as a counter-body and hardness of approximately $850 \mathrm{HV}$. The rotation speed and loads were $500 \mathrm{rpm}$ and 665, 1459 and $1826 \mathrm{~g}$ (6.65, 14.59 and $18.26 \mathrm{~N})$, respectively. Mean Hertzian contact stress for an AISI 52100 sphere pressed against a NbC plate was calculated as 360, 470 and $500 \mathrm{MPa}$, for the three studied loads [24].

Consecutive wear scars were produced for test times of $5,10,15$, and $20 \mathrm{~min}$ in order to obtain the volume loss curve for each applied load. Each test was repeated five times on the substrate and twice on the carbide coated steel. One sphere is used for a series of four tests $(5,10,15$ and $20 \mathrm{~min}$ ) and the sphere is slightly rotated after each test thereby creating a new circular mark around it at every test duration. The removed volume $(V)$ and the wear depth $(h)$ of each wear crater were calculated according to the following equations $[25,26]$ :

$V \approx \frac{\pi \times d^{4}}{64 \times R}$, for $d \ll R$

$h \approx \sqrt{\frac{V}{\pi \times R}}$, for $h \ll R$

where $d$ is the scar diameter, $h$ the wear depth and $R$ the sphere radius.

Additionally, corrosion tests were performed on coated and uncoated specimens in order to comparatively evaluate the electrochemical response of the systems. Experiments were made by means of potentiodynamic polarization tests. The electrochemical cell used to obtain the polarization curves utilized a saturated calomel reference electrode and a platinum auxiliary electrode. The electrolyte employed was an aqueous solution of $\mathrm{NaCl} 3.5 \mathrm{wt}$.\%. Prior to the tests the system was led to rest for $15 \mathrm{~min}$ and the open-circuit potential (OCP) acquired.

For monitoring the potential and current, an Autolab model PGSTAT302 potentiostat was applied. The polarization curves were obtained with a scanning speed of $1 \mathrm{mV} / \mathrm{s}$ from -1.0 to $1.125 \mathrm{~V}$. Each test was repeated twice and a representative curve is shown. For each experiment, $50 \mathrm{ml}$ of the electrolyte was employed and the area exposed to the saline solution was approximately $0.5 \mathrm{~cm}^{2}$.

\section{Results and interpretation}

\subsection{Metallography and X-ray diffraction}

In the present study, the AISI 52100 bearing steel was quenched in oil directly after the TRD treatment. Fig. 1 shows an electron micrograph and a EDS line scan from the cross section of the carbide coated sample. A continuous layer is observed over the base material, presenting a smooth interface with the substrate. Additionally, a small porosity is detected in the layer.

EDS line scan was performed perpendicularly from the top towards the base material and shows iron (Fe) and niobium ( $\mathrm{Nb}$ ) signals. Qualitatively, the analysis indicates a high niobium content on the layer, which decreases abruptly at the interface, where the iron amount from the substrate is detected. Residual aluminum was not found indicating that it is not incorporated into the carbide layer. The thickness of the layer measured directly on the electron microscope at different locations along the layer was about $6.1 \pm 0.1 \mu \mathrm{m}$. Moreover, the typical martensitic microstructure is verified below the compound layer which results from oil quenching.

Instrumented hardness was measured on the cross section of a hot mounted carbide coated steel on the diffusion layer and on the quenched substrate. AISI 52100 bearing steel has a hardness of about $64 \mathrm{HRC}$ ( $850 \mathrm{HV}$ or approximately $8.3 \mathrm{GPa}$ ) which results from the usually applied heat treatment conditions. The average value of $27 \pm 3 \mathrm{GPa}$ was obtained for the carbide layer, which is more than the double of the substrate hardness $(11 \pm 1 \mathrm{GPa})$. By means of hardness measurements on the cross section, no indication of a decarburized sub-surface zone was observed, after the TRD treatment. Such decarburization has been reported to develop as a consequence of carbon consumption to sustain the growth of the carbide layer [27].

The Poisson ratio of $\mathrm{NbC}$ as well as of the quenched AISI 52100 steel were taken from the literature as 0.21 [28] and 0.28 [29], respectively. Therefore, average elastic modulus of $\mathrm{NbC}$ and quenched AISI 52100 were estimated as $361 \pm 35 \mathrm{GPa}$ and $206 \pm 14 \mathrm{GPa}$, respectively.

Specialized literature indicates that elastic modulus of niobium carbide usually ranges from 338 to $580 \mathrm{GPa}$. Hardness of NbC depends on the metal to carbon ratio and a maximum of $25 \mathrm{GPa}$ is observed for a ratio of 0.8 decreasing to $20 \mathrm{GPa}$ when the ratio reaches the unit [28]. However, these properties are additionally dependent on the fabrication process, presence of impurities, etc. [28]. A study conducted by Orjuela G. and coworkers found hardness values of $26 \mathrm{GPa}$ for niobium carbide coatings produced by TRD on a carbon steel employing nanoindentation [21]. These values are in close agreement with the results of the present work.

In Fig. 2, an X-ray diffraction pattern of the coated AISI 52100 steel is shown. The narrow peaks confirm the presence of a cubic NbC layer on the surface of the substrate, according to ICDD card, number 38-1364. Additionally, ferrite peaks ( $\alpha$-Fe) are detected due to the penetration of the X-rays. These peaks actually correspond to martensite that is obtained after oil quenching the specimens directly from the salt bath after the treatment cycle $\left(1000{ }^{\circ} \mathrm{C} / 4 \mathrm{~h}\right)$. The results are in agreement with previously published research $[6,10,11,21]$.

Niobium carbide layers can be produced in borax salt bath treatment because this transition element has a relatively small free energy of 


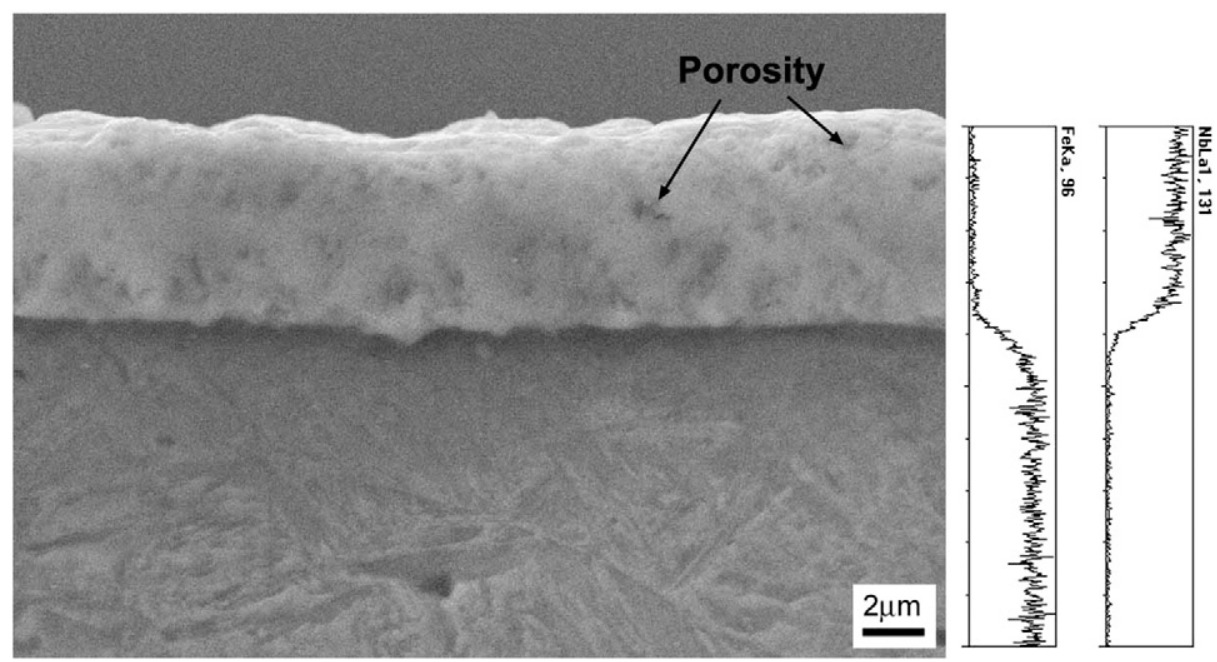

Fig. 1. Scanning electron micrograph of a carbide coated AISI 52100 steel produced at $1000{ }^{\circ} \mathrm{C}$ for 4 h with a line EDS scan for iron (Fe) and niobium (Nb).

carbide formation and a free energy of oxide formation which is higher than that of $\mathrm{B}_{2} \mathrm{O}_{3}[5,17]$. The layers are formed by the reaction of niobium atoms dissolved in the bath with carbon atoms present in the steel sample being treated. Thus it is important that the piece to be treated has a considerable carbon amount $(>0.3 \mathrm{wt} . \%)$ in its chemical composition [27].

Transition metal carbides, such as $\mathrm{NbC}$, with very high hardness have a great potential for wear applications $[6,10,11]$. Therefore, the next section deals with the evaluation of the wear performance of the produced coating.

\subsection{Wear characterization}

Wear is of extreme importance in numerous tribological systems. Coated and uncoated systems were characterized under identical conditions applying a micro-abrasive wear device with a fixed-ball configuration. Fig. 3 depicts the volume loss curves versus traveled distance, for the AISI 52100 steel substrate (Fig. 3a) and the NbC coated steel (Fig. 3b), at three different loads. The worn volumes were calculated using Eq. (1), based on the wear crater diameter $(d)$.

The worn volume of the AISI 52100 substrate increases as the applied load increase, and shows a tendency of stabilization along the traveled distance, for all three applied loads (Fig. 3a). Stabilization is usually expected in the present test configuration because at a fixed load the

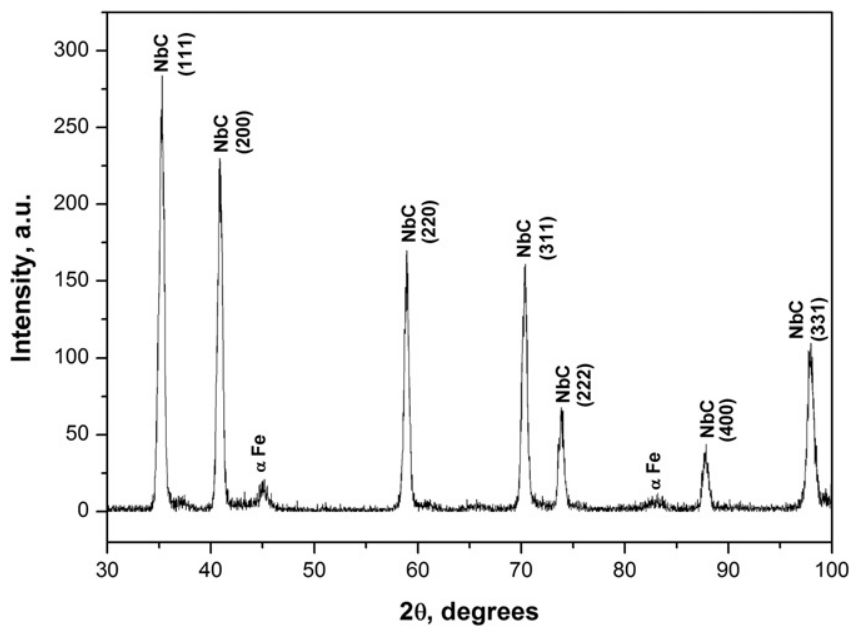

Fig. 2. X-ray diffraction pattern of the carbide coated AISI 52100 steel. wear crater increases along the test and thereby diminishing the applied pressure.

In the case of the $\mathrm{NbC}$ coated system (Fig. 3b) there is also an increment on the worn volume with the applied load. However, the total volume lost related to the three loads, were nearly 10 times less than that observed for the substrate, indicating a remarkable wear reduction after the TRD treatment. Moreover, the NbC coated AISI 52100 sample did not show a tendency of volume stabilization along the running distance. The $\mathrm{NbC}$ layer is perforated during the wear tests thus yielding an increase on the worn volume seen in Fig. $3 \mathrm{~b}$ (after about $420 \mathrm{~m}$ ).

Calculations based on the layer thickness and Eqs. (1) and (2) indicate that the maximum crater diameter to yield a layer perforation is $0.787 \mathrm{~mm}$ or $0.0014846 \mathrm{~mm}^{3}$ of volume. The dashed line in Fig. 3b indicates this maximum volume until the layer disruption. For all three test loads the NbC layer was disrupted although at different distances. By applying $18.26 \mathrm{~N}$ of normal load for example, the layer is disrupted within the first 5 min of wear testing.

Even after the breakdown of the NbC layer the substrate/layer wear rate seems to remain constant until $15 \mathrm{~min}(420 \mathrm{~m})$ of wear testing (Fig. 3b). This happens because most of the load is still sustained by the hard carbide layer and as the substrate is exposed wear gradually raises.

Although the tests were performed under dry condition, an abrasion wear mode was observed for both coated and uncoated systems at the three different studied loads. The wear debris from the contact region are responsible for the two-body abrasion (grooving) process which yields typical parallel scratches inside the wear tracks. In this case, the particles are essentially attached to the ball surface during the test and the grooves are produced by the micro-cutting action of these abrasive particles [30]. Since the niobium carbide layer has much higher hardness it can be assumed that the expected micro-cutting action of the abrasive particles is less effective what would lead to a lower wear rate when compared to the substrate.

A previous study by Oliveira et al. 2006, found similar results applying the same wear tests in a $\mathrm{NbC}$ layer produced by TRD on a tool steel (AISI H13). A decrease of more than ten times on the volume lost was observed after a $300 \mathrm{~m}$ of running distance employing a load of $18.7 \mathrm{~N}$ [6].

Fig. 4 plots the specific wear rate against the applied load for the AISI 52100 substrate and the $\mathrm{NbC}$ coated system. To estimate the specific wear rate $\left(\mathrm{mm}^{3} \cdot \mathrm{N}^{-1} \cdot \mathrm{m}^{-1}\right)$ from each volumetric loss curve (Fig. 3a and $\mathrm{b}$ ) at distinct applied load, linear regression was applied and the slope considered as the wear rate. In the case of the coated system only the first three points were used due to layer disruption, as previously discussed. The specific wear rate for the AISI 52100 steel clearly 

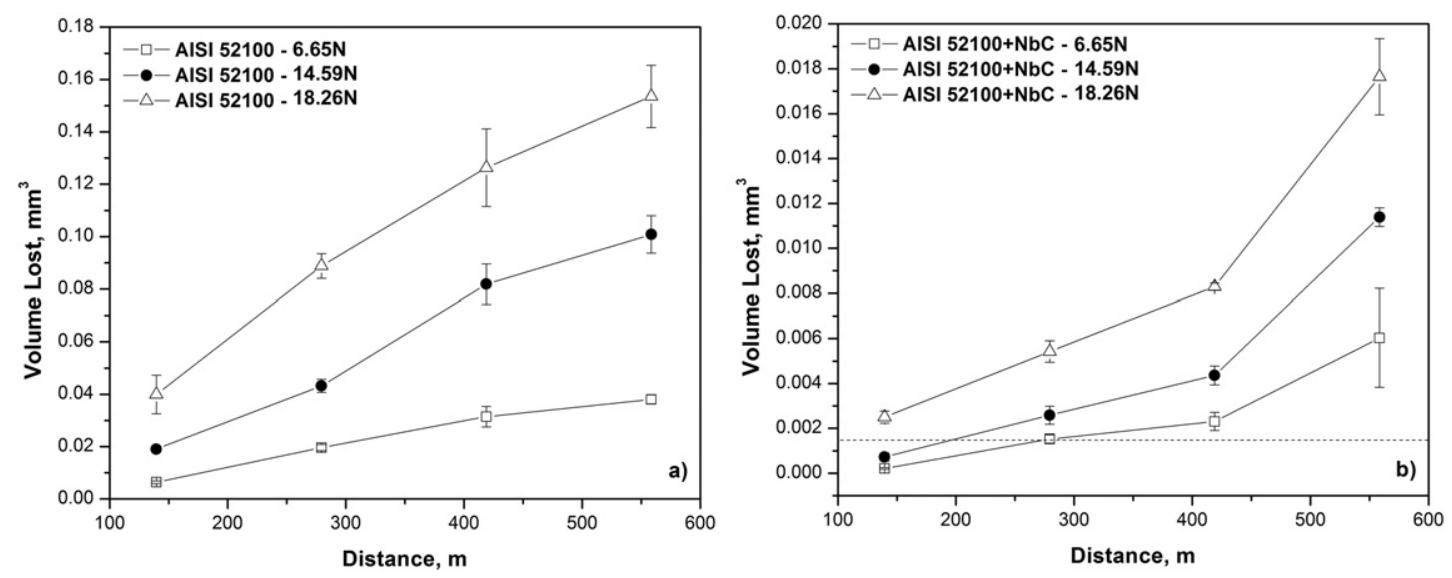

Fig. 3. Volume loss curves of the: (a) AISI 52100 substrate and (b) NbC coated AISI 52100, with 6.65, 14.59 and $18.26 \mathrm{~N}$ of applied load.

increases with load. Meanwhile nearly constant wear rates are seen for the $\mathrm{NbC}$ coated system, thereby indicating a significant enhancement on the tribological properties after the application of the TRD treatment.

Sen and Sen, 2008 studied the wear properties of a NbC coated AISI 1040 steel against alumina and AISI 52100 steel balls in a ball-on-disk configuration. The authors found wear rates for an $\mathrm{NbC}$ coating rubbing against steel and alumina, ranging from $1.44 \cdot 10^{-6}$ to 7.55 . $10^{-6} \mathrm{~mm}^{3} / \mathrm{N} \cdot \mathrm{m}$ for 2.5 and $10 \mathrm{~N}$ of normal load, respectively [10]. Such values commensurate with those obtained in the present work although applying a different test configuration. In the present case specific wear rates ranging from $1.3 \cdot 10^{-6}$ to $0.9 \cdot 10^{-6} \mathrm{~mm}^{3} / \mathrm{N} \cdot \mathrm{m}$ were obtained.

Such transition metal carbides are ceramic compounds with a very high hardness and exceptional wear properties. Numerous papers have already proved the feasibility of the TRD process to produce high hardness carbide layers and its potential for tribological applications $[6,10,11]$. However very few studies have dealt with the electrochemical behavior of transition metal carbides produced by TRD process.

\subsection{Corrosion}

Potentiodynamic polarization curves including both cathodic and anodic regions are shown in Fig. 5 for NbC coated and uncoated AISI 52100 steels. At negative (cathodic) potentials, the curves are very similar. However, when moving to positive (anodic) potentials the $\mathrm{NbC}$

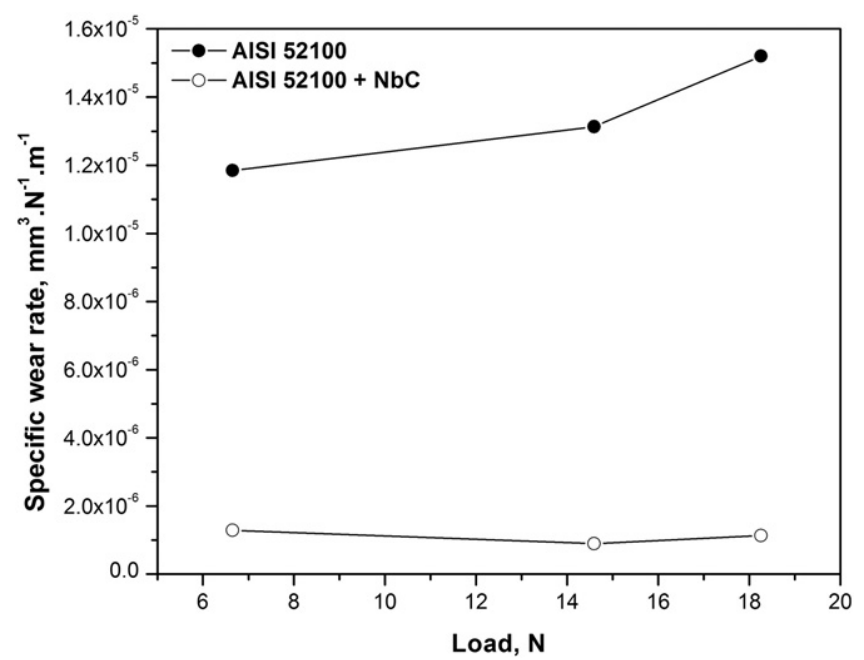

Fig. 4. Variation on specific wear rate $\left(\mathrm{mm}^{3} / \mathrm{N} \cdot \mathrm{m}\right)$ versus applied load $(\mathrm{N})$ for the substrate and the NbC coated AISI 52100 steel. coated curve appears shifted towards higher potentials indicating an improved behavior. At elevated anodic potentials $(>250 \mathrm{mV})$ both curves are again similar and the current density that runs through the systems is nearly equal $\left(\sim 60 \mathrm{~mA} / \mathrm{cm}^{2}\right)$. Both systems do not provide a satisfactory protection at this stage.

After examining the polarization curves in Fig. 5 the electrochemical parameters from $\mathrm{NbC}$ coated and uncoated AISI 52100 were collected and are presented in Table 1. The corrosion potential ( $\left.\mathrm{E}_{\text {corr }}\right)$, corrosion current density $\left(\mathrm{I}_{\text {corr }}\right)$ and open-circuit potential (OCP) give indications about the corrosion resistance of the studied specimens. Other parameters such as the anodic (ba) and cathodic (bc) Tafel slopes and the corrosion rate $(\mathrm{CR})$ were obtained as well.

Based on these parameters it is clear that the $\mathrm{NbC}$ coated system yields a more positive open-circuit potential, corrosion potential and additionally, a slightly lower corrosion current and corrosion rate. Therefore, the NbC layer confers a better response under the test conditions in the Tafel region where the cathodic branch meets the anodic one. Orjuela G. and coworkers suggested that improved corrosion resistance of niobium carbide coatings is probably due to the formation of niobium oxide $\left(\mathrm{Nb}_{2} \mathrm{O}_{5}\right)$ at the coated surfaces [21].

Examination of the corroded surfaces after the polarization allows an analysis of the operating corrosion mechanism. The AISI 52100 substrate underwent a generalized corrosion process in which dissolution takes place uniformly on the whole exposed area. Meanwhile, the $\mathrm{NbC}$

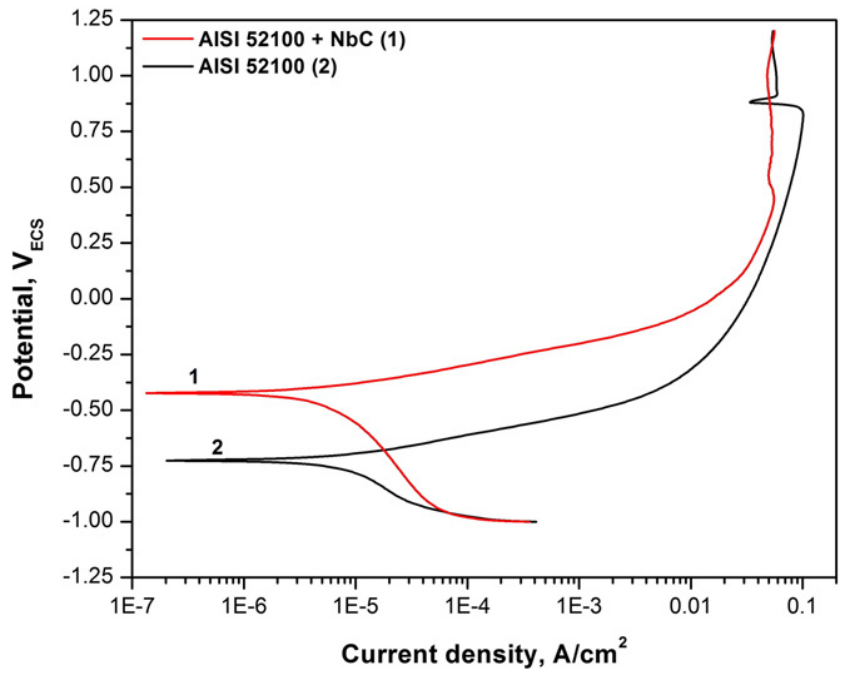

Fig. 5. Potentiodynamic polarization curves in aqueous solution for $\mathrm{NbC}$ coated and uncoated AISI 52100 steels. 
Table 1

Electrochemical parameters of the NbC coated and uncoated AISI 52100 steels.

\begin{tabular}{lllllll}
\hline Sample & $\begin{array}{l}\mathrm{I}_{\text {corr, }} \\
\mathrm{A} / \mathrm{cm}^{2}\end{array}$ & $\begin{array}{l}\mathrm{E}_{\text {corr, }} \\
\mathrm{mV}\end{array}$ & $\begin{array}{l}\mathrm{OCP}, \\
\mathrm{mV}\end{array}$ & $\begin{array}{l}\mathrm{bc}, \\
\mathrm{V} / \mathrm{dec} .\end{array}$ & $\begin{array}{l}\mathrm{ba}, \\
\mathrm{V} / \mathrm{dec} .\end{array}$ & $\begin{array}{l}\mathrm{CR}, \\
\mathrm{mm} / \mathrm{year}\end{array}$ \\
\hline AISI 52100 & $8.1 \times 10^{-6}$ & -725 & -590 & 0.339 & 0.073 & 0.070 \\
AISI 52100 + NbC & $4.3 \times 10^{-6}$ & -423 & -370 & 0.372 & 0.089 & 0.037 \\
\hline
\end{tabular}

coated system experienced a different corrosion mechanism that can clearly be noticed on the electron micrographs presented in Fig. 6 .

Fig. 6a depicts the corroded area showing several corrosion caps produced after polarization tests performed on the NbC coated AISI 52100. EDS analysis conducted inside (point 1 ) and outside (point 2 ) the corrosion caps indicate a very low niobium content inside a corroded crater/ cap. Therefore it is suggested that the NbC layer was somehow removed at different points on the layer.

An additional micrograph (Fig. 6b) was taken from a more magnified region outside the corrosion caps revealing the presence of small incipient pits. It is expected that these pits would allow the electrolyte to reach the steel substrate leading to the formation of corrosion products that press the layer upwards, thus yielding such corrosion caps seen in Fig. 6a.

Orjuela G. et al., 2014 recently studied the corrosion mechanism of $\mathrm{NbC}$ coating produced in borax salt-bath TRD on AISI 1045 steel. Polarization and impedance tests were performed in $3.0 \% \mathrm{NaCl}$ solution and indicated that saline solution reaches the substrate by penetrating trough the pores and defects present on the carbide layer. Furthermore, the authors did not observe corrosion caps after polarization and their work was conducted at a maximum scanning potential of $0.00 \mathrm{mV}$ [21]. In the present study up to $1.125 \mathrm{~V}$ was applied (see Fig. 5).

It is believed that such wide corrosion caps develop in a later stage during polarization at high applied potentials $(>250 \mathrm{mV})$ in which the current density is elevated and results on the massive formation of corrosion products beneath the carbide layer. In another work, Sun, 2010 verified corrosion caps in plasma carburized AISI 316L and suggested that the electrolyte would permeate the carburized case and reach the base alloy resulting on the formation of corrosion products that build up a pressure leading to a wide corrosion cap [31].

\subsection{Discussion}

The production of a carbide layer by the thermo-reactive deposition process depends strongly on the carbon content present on the steel employed. Steels with less than 0.3 wt.\% of carbon might suffer from decarburization beneath the case, due to carbon diffusion towards the surface to form the carbide layer [27]. The AISI 52100 has around
1.0 wt.\% of carbon which results in a homogeneous NbC layer as confirmed by EDS (Fig. 1) and XRD (Fig. 2) analyses.

Very high hardness was observed on the cross section of the carbide layer (about $27 \mathrm{GPa}$ ) and elastic modulus of $361 \mathrm{GPa}$. Previous work yielded similar hardness levels of $\mathrm{NbC}$ layers produced on a carbon steel by a TRD process [21,32]. Moreover, no difference in terms of hardness beneath the case and on the bulk was detected, indicating no significant decarburization of the base material. Such observation would validate the applied thermal cycle $\left(1000{ }^{\circ} \mathrm{C} / 4 \mathrm{~h}\right)$ to obtain hard carbide layers for practical applications. Accordingly, the carbon content of the steel must be considered as well.

Hardness fluctuations beneath the case would additionally impair wear performance in applications where increased load bearing capacity is required. Tribological tests indeed indicated improved wear resistance for the NbC coated AISI 52100 steel (see Fig. 3). A reduction of nearly 10 times on the worn volume was observed at a fixed load comparatively to the substrate. Additionally, increasing the applied load during the wear testing drastically increases the wear rate of the untreated steel. Meanwhile after the $\mathrm{NbC}$ deposition the wear rate is maintained at a low values for the three applied loads (Fig. 4). Such reductions in wear were previously observed in the literature for $\mathrm{NbC}$ layers produced by TRD process in a salt bath $[6,10]$. Moreover, wear microstructures are in agreement with those from previous work $[6,10]$.

Polarization experiments (see Fig. 4) suggest that niobium carbide layer presents an improved corrosion performance, although for applied potentials inferior than $250 \mathrm{mV}$. At higher potentials, both the substrate and $\mathrm{NbC}$ layer undergo significant corrosion damage. However, different mechanisms appear to operate on the substrate and on the layer. From the electron micrographs of the corroded NbC coating surface (Fig. 5), indeed it appears that the electrolyte access the substrate by permeating through the layer. Once the substrate begins to dissolve the resultant corrosion products build up a pressure on the layer thereby promoting a wide cap like seen in Fig. 5 a.

The present work corroborates the mechanism proposed by Sun, 2010 [31] which was additionally observed by Orjuela G. et al., 2014 [21]. Both authors suggest that the electrolyte reaches the substrate through the defects and/or porosity present on the layer. Moreover, previous studies on nitrocarburized [33] and deposited TiN films [34], both on AISI H13 tool steel, suggest that improved corrosion resistance is associated with lower porosity in the coating.

Thus, from the corrosion behavior perspective it seems important to develop alternative routes and methods to diffuse/deposit transition metal carbides in order to attain porosity-free coatings. Arai and Moriyama concluded that grain morphology, surface morphology and preferred orientation are greatly affected by the process parameters such as temperature, time and applied substrate [17]. It is estimated
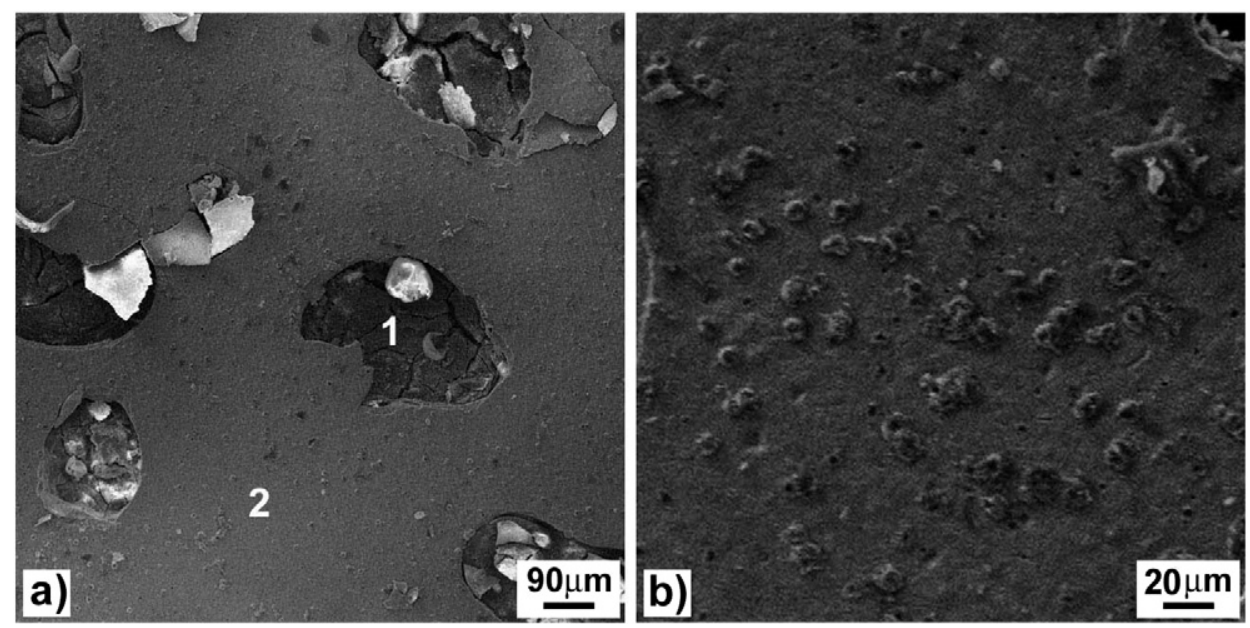

Fig. 6. Electron micrographs of the $\mathrm{NbC}$ coated AISI 52100 steel surface after potentiodynamic polarization testing. 
that porosity content is dependent on the applied process parameters as well. A recent work by Orjuela G. and collaborators suggests that porosity in the carbide layer decreases with the increase of ferro-niobium in the bath [21].

Therefore, a reduced porosity content may effectively prevent the electrolyte of permeating trough the layer. The production of lowporosity carbide layers could additionally provide higher hardness and improve even more the wear resistance of such coatings.

\section{Summary}

Thermo-reactive deposition in molten borax produced homogeneous niobium carbide coatings on AISI 52100 bearing steel. The layer is composed of cubic $\mathrm{NbC}$, as confirmed by EDS analysis and X-ray diffraction. Very high hardness (27 GPa) and elastic modulus that commensurate with previous studies were attained. Additionally, no significant decarburization was detected beneath the carbide case.

A hard carbide layer greatly enhances the wear resistance of the bearing steel. The worn volume increases as the load is increased, for both the substrate and the TRD treated system. However, worn volumes 10 times smaller are observed for the NbC coated AISI 52100 steel.

Potentiodynamic polarization experiments indicate an improved behavior for the $\mathrm{NbC}$ coated steel in $3.5 \% \mathrm{NaCl}$ solution, comparatively to the untreated substrate, for potentials lower than $250 \mathrm{mV}$. The corrosion process on the $\mathrm{NbC}$ coating takes place in a localized manner where the saline solution penetrates through the layer reaching the substrate then leading to the occurrence of wide corrosion caps.

\section{Acknowledgments}

Frederico A.P. Fernandes is grateful to the CNPq Brazilian council for the scholarship granted under the process number 314195/2014-9.

\section{References}

[1] T. Arai, S. Harper, ASM Handbook, vol. 4, ASM International, Materials Park, $\mathrm{OH}$ 1991, p. 448

[2] L.C. Casteletti, F.A.P. Fernandes, S.C. Heck, C.K.N. de Oliveira, A. Lombardi-Neto, G.E Totten, Heat Treat. Prog. 9 (2009) 49-52.
[3] X.S. Fan, Z.G. Yang, C. Zhang, Y.D. Zhang, H.Q. Che, Surf. Coat. Technol. 205 (2010) 641-646.

[4] A. Bendavid, P.J. Martin, T.J. Kinder, E.W. Preston, Surf. Coat. Technol. 163-164 (2003) 347-352.

[5] T. Arai, S. Moriyama, Thin Solid Films 249 (1994) 54-61.

[6] C.K.N. Oliveira, R.M. Muñoz Riofano, L.C. Casteletti, Surf. Coat. Technol. 200 (2006) 5140-5144.

[7] U. Sen, Thin Solid Films 483 (2005) 152-157.

[8] F.A.P. Fernandes, S.C. Heck, C.A. Picon, G.E. Totten, L.C. Casteletti, Surf. Eng. 28 (2012) 313-317.

[9] K. Genel, Vacuum 80 (2006) 451-457.

[10] S. Sen, U. Sen, Wear 264 (2008) 219-225

[11] C.K.N. Oliveira, C.L. Benassi, L.C. Casteletti, Surf. Coat. Technol. 201 (2006) 1880-1885.

[12] T. Arai, H. Fujita, Y. Sugimoto, Y. Ohta, J. Mater. Eng. 9 (1987) 183-189.

[13] M. Woydt, H. Mohrbacher, Wear 306 (2013) 126-130.

[14] B. Sustarsica, M. Jenikoa, M. Godeca, L. Kosec, Vacuum 71 (2003) 77-82.

[15] U. Sen, Mater. Chem. Phys. 86 (2004) 189-194.

[16] S.M.M. Khoee, A. Ata, A.E. Geckinli, N. Bozkurt, Mater. Sci. Forum 163-165 (1994) 627-632.

[17] T. Arai, S. Moriyama, Thin Solid Films 259 (1995) 174-180.

[18] S. Hotta, Y. Itou, K. Saruki, T. Arai, Surf. Coat. Technol. 73 (1995) 5-13.

[19] H. Tavakoli, S.M. Mousavi Khoie, Mater. Chem. Phys. 124 (2010) 1134-1138.

[20] I. Mejía-Caballero, J. Martínez-Trinidad, M. Palomar-Pardavé, M. Romero-Romo, H. Herrera-Hernández, O. Herrera-Soria, I. Campos Silva, J. Mater. Eng. Perform. 23 (2014) 2809-2818.

[21] A.G. Orjuela, R. Rincón, J.J. Olaya, Surf. Coat. Technol. 259 (2014) 667-675.

[22] Q.Y. Wang, H. Zhang, M.R. Sriraman, S.X. Li, Key Eng. Mater. 297-300 (2005) 1846-1851.

[23] ISO 14577-1, Metallic Materials - Instrumented Indentation Test for Hardness and Materials Parameters - Part 1: Test Method, International Standard ISO, Geneva, 2002 (32 pp.).

[24] K.L. Johnson, Contact Mechanics, Cambridge University Press, UK, 198793 (1-462).

[25] K.L. Rutherford, I.M. Hutchings, J. Test. Eval. 25 (1997) 250-260.

[26] K.L. Rutherford, I.M. Hutchings, Surf. Coat. Technol. 79 (1996) 231-239.

[27] B. Chicco, W.E. Borbidge, E. Summerville, Mater. Sci. Eng. A 266 (1999) 62-72.

[28] H.O. Pierson, Handbook of Refractory Carbides and Nitrides, Noyes Publications, Park Ridge, N.J., 1996.

[29] G.Y.B. Guo, C.R. Liu, J. Manuf. Sci. Eng. 124 (2002) 1-9.

[30] K. Adachi, I.M. Hutchings, Wear 255 (2003) 23-29.

[31] Y. Sun, Corros. Sci. 52 (2010) 2661-2670.

[32] F.E. Castillejo, D.M. Marulanda, J.J. Olaya, J.E. Alfonso, Surf. Coat. Technol. 254 (2014) 104-111.

[33] R.L.O. Basso, R.J. Candal, C.A. Figueroa, D. Wisnivesky, F. Alvarez, Surf. Coat. Technol. 203 (2009) 1293-1297.

[34] Y.H. Yoo, D.P. Le, J.G. Kim, S.K. Kim, P.V. Vinh, Thin Solid Films 516 (2008) 3544-3548. 